\title{
La Relación HeIdegger y HaNnah ARENdT, SEMEJanZas y DIFERENCIAS FILOSOFICAS
}

\author{
[The Relation Between Heidegger and Hannah Arendt, PHILOSOPHiCAL APPROACHS \\ AND DIFFERENCES]
}

\begin{abstract}
RESUMEN: En el presente trabajo, nos interesa presentar a Martin Heidegger y Hannah Arendt de manera que, sin juicios de valor, podamos adentrarnos en su filosofía $y$ en las consecuencias políticas que de ella se derivan. La filosofía no es inocente. En el caso de Heidegger, siguió el camino del existencialismo, de la ontología, con cierta fascinación por Hitler, lo que le ocasionó una pérdida de credibilidad en los círculos filosóficos de aquella época. Arendt por su parte, a más de ser víctima del nazismo, eligió el camino de la teoría política, justamente para defender a los pobres en derechos, aquellos ciudadanos excluidos de los espacios políticos, donde participan únicamente los especialistas que gestionan la política. De ahí que la vía de Arendt, sea una labor de resistencia y de reconstrucción ciudadana.
\end{abstract}

Palabras Clave: Heidegger, H. Arendt, política, libertad, pensamiento.
Abstract: In this work, we present Hannah Arendt and Martin Heidegger's legacy in a way in which, without value judgments, we explore their philosophy and the political consequences arising from it. Philosophy is not innocent. In the case of Heidegger, it followed the path of existentialism and ontology, with some fascination with Hitler, resulting in a loss of credibility within the intellectual circles of the time. Arendt on the other hand, besides being a victim of Nazism, chose the path of political theory, just to defend the rights of those excluded from political participation, a realm controlled by the specialists who manage policy. Therefore, Arendt's work is the expression of a commitment to resistance and civic reconstruction.

KeYwords: Heidegger, H. Arendt, política, libertad, pensamiento.

\section{INTRODUCCIÓN}

M ucho se ha escrito acerca de la relación entre Martin Heidegger y Hannah Arendt. Sus aspectos afectivos e intelectuales han provocado múltiples opiniones. Algunos han preferido señalar, en coincidencia con Arendt, que se debe distinguir nítidamente lo que corresponde al espacio privado, del público. De ahí que en el trabajo que nos ocupa, no intentaremos adentrarnos en la vida privada de los dos pensadores, siendo las referencias en ese ámbito, las estrictamente imprescindibles.

La relación profesor - estudiante entre Heidegger y H. Arendt se inicia en las aulas universitarias allá por el año 1920. Al comienzo fue muy discreta, pero que con el

* Doctor (PhD) en Filosofia por la Universidad de Estrasburgo, Francia. Docente investigador de la Universidad Nacional de Chimborazo, Ecuador, en la Facultad de Ciencias Políticas y Administrativas. m@ilto: gnieves@unach.edu.ec / gnievesloja@yahoo.es 
pasar del tiempo, no era desconocido para el mundo intelectual, su conexión no solamente filosófica, sino afectiva. Heidegger confesó su felicidad a lado de Arendt y, la consideró como algo "providencial del Ser". Por su parte, ella se refirió a él como la "bendición de su vida". No cabe duda entonces del afecto que sintieron los dos pensadores, aunque las situaciones académicas y de coyunturas políticas del nazismo de Hitler, los separaron geográficamente.

Posteriormente, esta relación se pudo reconstruir cuando Arendt vivía en Estados Unidos y ayudó considerablemente a la difusión de la obra de Martin Heidegger. Cabe mencionar que fue ella la mejor publicista y embajadora de la obra de Heidegger, debido a que su pasado nazi, había afectado considerablemente el ámbito de la comunidad filosófica internacional. En cierto sentido es Arendt quien suaviza la imagen de Heidegger.

En el presente trabajo nos interesa presentar a estos dos pensadores, de manera que sin juicios de valor, podamos adentrarnos en su filosofía y en las consecuencias políticas que de ella deriva. La filosofía no es inocente. En el caso de Heidegger, siguió el camino del existencialismo, de la ontología, con cierta fascinación por Hitler, lo que le ocasionó una pérdida de credibilidad en los círculos filosóficos de aquella época. Arendt por su parte, a más de ser víctima del nazismo, eligió el camino de la teoría política, justamente para defender a los pobres en derechos, aquellos ciudadanos excluidos de los espacios políticos, donde participan únicamente los especialistas que gestionan la política. De ahí que la vía de Arendt, sea una labor de resistencia y de reconstrucción ciudadana.

Para Arendt es fundamental la capacidad de pensar por sí mismos, pero, ¿por qué ella considera tan importante esta facultad humana en la construcción de lo político? Es justamente en este campo donde Arendt recurre a Sócrates quien, considerado como ejemplo de buen ciudadano, invita a pensar en sus semejantes, sin buscar el poder por sí mismo. El totalitarismo de Hitler redujo a los ciudadanos a seres que no pensaban y que repetían frases clichés. El segundo apoyo lo encuentra en Kant, cuyo pensamiento ampliado se constituye en fundamento ético y político del razonamiento. Podríamos preguntarnos, ¿por qué Kant se constituye en el referente mayor del quehacer político en la obra de H. Arendt?

Seguidamente analizaremos la crítica que hace al concepto cristiano de la libertad según de Pablo de Tarso, y el elogio al paradigma de la Grecia clásica y las leyes romanas de la antigüedad. Arendt realiza un elogio remarcable de la revolución norteamericana. ¿Qué es lo que busca en este retorno a la sabiduría clásica?

Luego nos adentraremos en el pensamiento de Heidegger, primero su fascinación ciega por Hitler. ¿Cómo pudo un pensador de tanto prestigio caer y dejarse convencer por la propagan nazi? Su amigo Jaspers le advertía del peligro inminente para la nación alemana.

En la siguiente parte iremos al punto central de nuestro trabajo. Analizaremos, cómo Heidegger y Arendt emprenden un plan de retorno a la sabiduría clásica. Esta es la mayor semejanza de método que poseen ambos pensadores. Según ellos, hay que ir a los orígenes para recuperar el verdadero sentido de los conceptos tradicionales, que a lo largo de la historia no se han interpretado correctamente. Es aquí donde veremos el alejamiento de $\mathrm{H}$. Arendt respecto al pensamiento de Heidegger. Ella elabora su propia teoría, sin la aprobación de su maestro quien, en vez de felicitarla, manifiesta cierta indiferencia. ¿Cuáles son esos distanciamientos políticos? ¿Por qué los dos desembocaron en espacios tan diferentes e incluso opuestos? El uno aplaudía a Hitler, mientras que la otra lo criticó fuertemente. ¿Son complementarios, se deben mutuamente? 


\section{LA OPCión POLÍtica de HANNAH ARENDT}

Según H. Arendt, lamentablemente, el mundo común fue destruido con la aparición de lo social y del ser humano moderno, del imperialismo y del sistema totalitario del nacional - socialismo de Hitler. Es el mundo de la modernidad, del oikosnomia, que provoca la desaparición de la acción y de la palabra del hombre político, para dar paso a una sociedad conformista, donde el único objetivo es fabricar herramientas (homo faber) y trabajar (homo laborans) para tener una propiedad. Los ciudadanos ya no piensan, repiten frases que manda repetir la propaganda. Vamos a iniciar escuchando a esta pensadora judío - alemana que elabora una propuesta de denuncia y de reconstrucción política.

\subsection{La incapacidad de pensar y sus consecuencias políticas}

El pensamiento político de Arendt constituye "una resistencia y una reconstrucción" (Ricoeur 2002, p. 14) frente a la tradición filosófica que dividía al pueblo entre gobernantes y gobernados, entre los que saben y los que no saben. En esta tradición, la de la metafísica contemplativa de la modernidad, el hecho de pensar, era privilegio de una minoría. El pensador debía ser profesional de la filosofía, para que pueda ser acogido en los círculos de los especialistas, debía practicar la especulación y el cogitare. Arendt siempre renunció a ser tratada como una profesional de la filosofía.

H. Arendt considera que se puede pensar sin ser un pensador profesional de la política o de la filosofía. Para argumentar esta propuesta, ella se remonta al pensador Sócrates. Este sabio griego antes que todo era un buen ciudadano, un pensador de la pluralidad y de lo político. Consideraba que se debía ser amante de la justicia, de la belleza y de la sabiduría para construir un mundo común. Ayudaba a los ciudadanos de Atenas a ejercer su reflexión y a despertar en ellos un sentido crítico, para que, de esta manera, nazcan amigos de la ciudad, personas capaces de entender los problemas que hay en la polis. Hombres capaces de pensar, de "dar a luz" nuevas ideas para el buen vivir de los ciudadanos en la polis griega.

En un primer sentido, el pensar es un acto silencioso, un diálogo consigo mismo, es la perfecta concentración que anula las distancias temporales y espaciales, y está en relación con el sentido común y el recuerdo. Es la fuente de la libertad. En una segunda instancia, el pensar es como una práctica entre seres humanos. El ser humano común piensa como miembro de la pluralidad humana, donde coexisten distintos puntos de vista. Se piensa poniéndose en el lugar de cualquier otro ser humano. El pensamiento es crítico, sin proponerse otro propósito u objetivo. Entonces, se tiene que entender lo que el otro está pensando, porque es a través de la comprensión, como nos reconciliamos con la realidad. En este sentido la comprensión es política, y se manifiesta en el vivir juntos en un mundo común, y es para todos.

Con el nacimiento del imperialismo, la libertad política se finiquita, se da prioridad a la clase dominante capitalista, y la violencia se instala, teniendo como resultado, la abundancia de dinero y seres humanos superfluos que no piensan. El filósofo Hobbes es el representante de la burguesía, el defensor de la adquisición de riquezas, concebidas como un proceso perpetuo de acumulación. De esta manera, el ciudadano pierde el sentido común y la razón política. Esta situación condujo al sistema totalitario que utilizó el nacional - socialismo alemán de Hitler, y constituyó su arma ideológica.

El sistema totalitario de la Alemania nazi y el comunismo de Stalin en Rusia, 
fueron la expresión extrema de la voluntad de dominación y del terror bruto. Se trató de un totalitarismo que obedecía a las leyes de la historia o de la naturaleza, y que provocó el nacimiento del hombre de masa por raza (Hitler) y por clase (Stalin). Estos hombres vivían en el aislamiento, incapaces de tener relaciones sociales normales. Es desde esta masa, desde donde los dictadores querían que surgiera una nueva comunidad. Pero para eso se tenían que eliminar las opiniones disidentes. Esta comunidad destruyó toda tradición social, política y jurídica, haciendo que sus integrantes sean incapaces de comprender y de pensar por sí mismos. No podían comunicarse con los demás, fueron reducidos a una unidad despersonalizada y perdieron toda espontaneidad. Esto trajo como consecuencia la separación de la libertad y lo político. En este punto del argumento, Arendt recurre a Kant.

H. Arendt considera que la facultad de juzgar (Kant) es una actividad política, que nos invita a pensar poniéndonos en lugar del otro en un espacio público, en el que se juzga desde la perspectiva de todos. El juicio implica el sentido común que presupone un mundo compartido. Tenemos un sentido que regula todos los datos sensibles y, que son para nosotros absolutamente personales, y los articula con los de todos los demás individuos. El juicio, o gusto, es una capacidad política que humaniza realmente lo hermoso y crea una cultura. Aquí lo bello no es una obra de arte, es más bien lo bello de la participación ciudadana en un espacio público. Lo esencial está en el significado que se debe otorgar al modelo estético-político en la frase de Pericles, citada por Tucídides: "Amamos la belleza al interior de los límites del juicio político, y filosofamos sin el vicio bárbaro de la debilidad". Tal vez Pericles quiso decir que el amor a la belleza debe acompañarse con un cierto sentido común, cierto buen gusto que se puede calificar, en el más amplio sentido, de "política" (Deruelle, 1993, p. 39). Este gusto por lo político, tiene una base fundamental que es la libertad, manifestada por los ciudadanos cuando toman la palabra y participan en los debates públicos.

\subsection{El paradigma de la libertad política}

Arendt asume una actitud crítica frente a la libertad del cristianismo defendida por San Pablo. Ella rechaza también la concepción de comunidad de San Agustín, debido a que se considera al ser humano culpable desde sus orígenes. No hay razón para firmar que "todos somos culpables". Según Arendt, la libertad es pública. Donde los ciudadanos actúan, toman la palabra y participan. Para sustentar estos principios, Arendt se remonta a los paradigmas del pueblo griego, de Roma y de la revolución norte americana.

En el pueblo griego, en la polis y su Constitución, el hombre era considerado como biopolitikos, es decir, un hombre de acción y de palabra. En el caso de los romanos, había una autoridad para regular la conducta de los ciudadanos. Las personas tenían derechos y deberes. En cuanto a la Revolución americana, fue un acontecimiento capaz de crear nuevos centros de poder, estableciendo un órgano político que garantizaba espacio donde la libertad podía aparecer. No así la Revolución francesa, cuya limitante fue inspirarse en la compasión y la piedad, que son categorías prepolíticas, categorías de liberación y no de libertad. Aquí el cuerpo político se basaba en los derechos naturales del hombre. La Constitución interesaba más a los estudiosos y a los especialistas que al pueblo pobre.

Lo Arendt quiere defender es la comunidad política, la cual es constitucional y no es cultural, ni religiosa, ni de origen natural. Proviene de una pluralidad de puntos de vista opuestos y argumentados. Esta comunidad requiere de un espacio público. No se 
busca el bien común, sino el bien público, y los ciudadanos viven en un Estado que tiene derechos y deberes. Pero, ¿por qué se afana H. Arendt en promover la comunidad? Simplemente porque los totalitarismos y, particularmente, el nazismo la destruyó, reduciendo a los ciudadanos a seres separados y aislados de toda comunicación con sus semejantes. Esto significa morir a la ciudadanía, a la cual fue reducida el pueblo judío.

Algunos críticos de Arendt, como es el caso de Habermas, afirman que no es justa la radicalización de la política en detrimento de lo social. Habermas además considera que el concepto de Arendt de política es poco aplicable a las situaciones contemporáneas, sobre todo en América Latina. Los puntos más vulnerables son: un Estado descargado del tratamiento administrativo de los asuntos sociales; una política liberada de las cuestiones de política social; una institucionalización de la libertad pública independiente de la organización del bienestar" (García 2001, p. 200). Parece que la teoría política de Hannah Arendt puede ser disfrutada por unos pocos: las élites que se auto-eligen. Mientras que las masas y los pobres estarían inhabilitados por su propia condición, ya que, según Hannah Arendt, solo pueden ser libres, aquellos que han cubierto sus necesidades básicas. Arendt intenta dar cuenta de este mal característico del mundo moderno y que domina la "cuestión social", aquello que podríamos llamar el asunto de la pobreza. Ella afirma que el éxito de la Revolución americana radicó en el hecho de que la pobreza estuvo ausente (García, p. 2004).

En todo caso Arendt defiende lo político, debido a que el triunfo de lo social acabó con las voces disidentes, con aquellos que pensaban diferente. Heidegger fue adversario de cualquier democracia participativa y pluralista, amigo de un cambio y una renovación - revolución cuyo héroe vio en Hitler (Heidegger, 1977, p. 99). De ahí su fascinación por él.

\section{Hitler fascina A Heidegger}

A pesar de la ontología de la libertad, Heidegger se afirma en "Ser y tiempo" como un adversario de la democracia pluralista, totalmente opuesto a la afirmación de H. Arendt. Durante el curso de invierno 1931-1932, Heidegger toma posición a favor del nacional-socialismo. El ve en este partido un factor de orden frente a la crisis económica y del caos de la república de Weimar. Pero cabe recalcar que esta posición, no se refleja aun en su filosofía de aquel momento histórico.

Sin embargo, un año más tarde Heidegger creerá que el instante de la acción ha llegado. El éxtasis parece súbitamente ser posible en la política, y él quería hacer alianza con las fuerzas que manifiestan una verdadera voluntad de cambio y renovación. Tenía la esperanza que el nacional-socialismo reconociera y asimilara todas las fuerzas constructivas y productivas.

Como podemos ver, Heidegger evoca motivos racionales y no habla de su entusiasmo revolucionario. Según él, una nueva era se abriría con Hitler (Safranski 1996, p. 243). El ser al fin ha llegado. "Todos estamos bajo las órdenes de una nueva realidad" (Heidegger, 1977, p. 100). Es el momento en que la filosofía se deja absorber por la realidad política, y es cuando Heidegger, no solo tenía cosas que decir a Hitler, sino que le creía capaz de trascender el partido y la doctrina. El filósofo estaba convencido de que esta corriente podría ser orientada por otros caminos intelectuales y que, una forma de responsabilidad occidental, vería el día en su fundación del cambio y de encuentro (Safranski, p. 246).

Heidegger se dejó fascinar por Hitler, de ahí que el 3 de noviembre de 1933, dirigiéndose a los estudiantes alemanes dijo: "No tomen los principios e ideas como 
reglas de su ser. Solo el Führer, el mismo, es la realidad y la ley de la Alemania de hoy y del mañana”. El pensador alemán Jaspers, crítico del nacional-socialismo, pregunta a Heidegger: ¿Cómo un hombre (Hitler) tan inculto puede gobernar Alemania?, Heidegger responde "la cultura no cuenta (..), mire pues sus admirables manos" (Safranski, p. 247).

Sin embargo, aunque Heidegger haya conservado su fe en Hitler y en la necesidad de una revolución, poco a poco comienza a desinteresarse y distanciarse de la política. El buscó un héroe para su filosofía, y encontró un héroe político. Hacia 1934, Heidegger da un viraje hacia el espíritu que desembocará en otro héroe: Hölderlin, de manera que el pueblo alemán pueda encontrarse consigo mismo (Heidegger, 1973, p. 2002).

Según Heidegger, la filosofía debe transformarse en un elemento de la realidad revolucionaria, la cual no puede ser vivida más que por aquel que es capaz de vivirla, y no por el observador. Ella se encuentra en la esencia del comenzar, en el nacimiento de una nueva comunidad; frente a lo cual hay que comprometerse (Heidegger, 2012, p. 14).

¿De qué revolución está hablando Heidegger? Una revolución nacionalsocialista debería permitir llevar a cabo correctamente una reforma racional de la Universidad alemana. Sin embargo, no se trata de un cambio de estructuras sociales o políticas, sino una renovación del espíritu occidental después de la "muerte de Dios". Esta revolución es realizada por los fuertes, los temerarios y los resueltos, en una franca oposición contra la obsesión tecnicista y mecanicista de las ciencias modernas (Safranski, p. 292).

¿Heidegger es antisemita? Él no lo era en el sentido de un sistema ideológico obsesional a la manera de los nacional-socialistas de Hitler. No se han encontrado huellas antisemitas, ni en sus cursos, ni escritos filosóficos, como tampoco en sus discursos y panfletos políticos. El soñaba con "la construcción de un nuevo universo espiritual para el pueblo alemán”. Aunque es verdad que participó del despido de profesores judíos de las universidades y se alejó de su maestro judío Husserl; sin embargo, nunca habló de protegerse del "espíritu judío" (Safranski, p. 263).

H. Arendt fue discípula de Heidegger durante un tiempo, de ahí la inclinación por la sabiduría de los clásicos, aunque ella antes de estudiar con su maestro, ya conocía partes importantes de la filosofía griega. En todo caso, vamos a ver en qué aspectos los dos pensadores emprenden un camino de ir a las fuentes griegas y romanas.

\section{El PLAN RETORno de HeIDEgGer y ARENDT}

En primer lugar debemos señalar la ruptura que se produce en la relación intelectual entre Hannah Arendt y Heidegger. De hecho ella escribe: "Se puede decir que toda mi vida le hice creer como si no entendiera (a Heidegger), siempre he hecho como si todo eso no existiera, como si no supiera contar hasta tres; él siempre estaba muy feliz de que yo supiera contar hasta tres e, incluso, hasta cuatro, a veces. Y luego perdí el afán de engañar y de inmediato recibí un golpe" (Arendt, 2006, p. 279). Y llegó el momento de la independencia que Hannah Arendt asume en relación con Heidegger.

Según Heidegger, pensar se parece a un retroceso, y él practica el retroceso cuando somete su libro Ser y Tiempo (Sein und Zeit) a una crítica inmanente (Heidegger, 1986, p. 361). Con Heidegger, el pensamiento se vuelve nuevo y vivo. Él logra hablar de los tesoros culturales del pasado que se creían muertos y ofrece entonces cosas bien diferentes de lo que habíamos pensado, no sin recelo (Cassin, 1996, 
p. 21). Para ello recurre a la sabiduría griega y romana; su obra inaugura una nueva filosofía recurriendo al rescate y a la reformulación de conceptos mal definidos a lo largo de la historia.

Heidegger también completó "el derrumbe del edificio de la metafísica en vigor, en donde, de todos modos, nadie, desde hacía mucho tiempo, se sentía muy cómodo, ya que se practicaban galerías y trabajos de destrucción" (Arendt, 2000, p. 226). Arendt añade que con "Heidegger, dejamos la arrogancia de todos los Absolutos atrás de nosotros", lo que significa que el filósofo abandonó la pretensión de la "sabiduría" y del conocimiento de modelos eternos, en beneficio de los asuntos perecederos de la ciudad de los hombres" (Arendt, 228). Cada uno de los escritos de Heidegger es como un nuevo comienzo.

El paso atrás de Heidegger, es el retorno a la ontología griega. En Hannah Arendt también hay una división y una evocación igualmente a los presocráticos. Pero no son los mismos presocráticos: los presocráticos de Hannah Arendt son el paradigma de una experiencia "prefilosófica". Como "filosófico" o "teórico", el corpus griego va, para Hannah Arendt, de Parménides a Platón, y de Aristóteles hasta Heidegger. Los presocráticos de Heidegger, incluso Anaximandro, son modernos, según Hannah Arendt.

Heidegger y Hannah Arendt quieren descubrir los verdaderos orígenes de los conceptos tradicionales con el fin de extraer de nuevo el espíritu originario, que se "evaporó tan tristemente de las palabras, clave aún de la lingüística política, dejando atrás de él cáscaras vacías listas para servir en cualquier oportunidad" (Cassin, p. 21). De hecho, es importante, no tanto tener ojos para el fenómeno, sino tener oídos para el pasado.

En este retroceso, la relación entre Roma y Grecia es, para Heidegger y Hannah Arendt, una relación de traducción-traición. Heidegger evoca el latín para decir cuánto la traducción de los términos griegos traiciona la experiencia griega, por ejemplo l'aletheia convirtiéndose en veritas, el zoonpolitikon transformado en animal socialis. Para Hannah Arendt, esta sustitución de lo político por lo social supone la pérdida de la concepción originaria griega de la política (Arendt, 2002, p. 32). Una vez más, el pensamiento romano recoge las palabras griegas sin entender su significado; es decir, sin la palabra griega. Por eso Hannah Arendt señala que los romanos no tenían oído para Grecia, ni a nivel filosófico, ni a nivel político (Cassin, p. 25). Para Heidegger, nosotros pensamos lo político de la manera romana, es decir de modo imperial.

Por otro lado, si hay para Heidegger dos Aristóteles, uno presocrático y otro ya moderno, Hannah Arendt igualmente tiene dos Aristóteles, uno pre-filosófico y político, y el otro platonicista y teorético. Ambos son lectores de Aristóteles. El proyecto central de Heidegger en su tiempo era establecer una ontología fundamental; es decir, una ciencia de los sentidos del ser, cuyo tiempo es la casa-hogar. "El aletheuein consiste en revelar y en caracterizar la verdad como un estado revelado, que toda automanifestación del ser explica" (Taminiaux, 1998, p. 43).

La reapropiación heideggeriana del análisis aristotélico de la poesía (poiesis) y de la actividad (praxis), está motivada por una única búsqueda: la de la unidad semántica de los sentidos del ser. No nos preguntamos cómo actuar, sino cómo entender el ser como tal. Uno puede preguntarse si eso no lleva a considerar la actividad de pensar el ser, como la forma más verdadera de la praxis.

Hannah Arendt y Heidegger se preguntan cuál es el bios (vida) más alto, Hannah Arendt considera que el bios es la existencia específicamente humana. Para Heidegger, es en el theorein, como investigación pura del ser como tal, en la que el hombre alcanza la mayor proximidad posible hacia el modo de ser más alto que le es accesible. Con 
Hannah Arendt, como lo establecen adecuadamente los comentaristas más perspicaces, se encuentra "resucitado el concepto aristotélico de la polis, de lo político y de la ciudadanía" (Taminiaux, p. 48).

Si bien es cierto que H. Arendt fue discípula de Heidegger, ella emprende otro camino, separándose del maestro que la fascinó en Marburgo - Alemania. Ella concede una singular importancia al espacio público, como lugar de libertad y de pluralidad, donde los ciudadanos tienen derecho a tener derechos. Cabe recordar también que la opción de su antiguo maestro por el partido nacional - socialista alemán, afectó su memoria nostálgica, llena de recuerdos afectivos e intelectuales.

\section{Hannah Arendt Se aleja de Heidegger}

Para Heidegger, es de suma importancia que la ciudad sea pensada desde abajo, es decir desde la realidad. En esto consiste el "a-politismo"de Heidegger donde actores, creadores y fundadores forman un solo ente. Heidegger propone entender la Polis (ciudad, Estado) a partir de Pélein, el antiguo verbo para einai: la ciudad es en sí, el lugar de la revelación total del ser. La diferencia entre el Estado moderno, la res pública romana y la polis griega, es exactamente la misma que hay entre la esencia moderna de la verdad, la rectitudo romana y la aletheia griega.

Heidegger no escribe bajo el temor de un arma nuclear o de una tercera guerra mundial. Para él, el verdadero peligro reside más bien en la dominancia del pensamiento calculador. Sin embargo una guerra nuclear, según Hannah Arendt y Heidegger, destruiría la posibilidad de hablar, de actuar en conformidad, y causaría la pérdida irrecuperable de las relaciones humanas. Por lo tanto, los sobrevivientes de la guerra no pertenecerían más a la humanidad (Courtine-Denamy, 1998, p. 18). Según Hannah Arendt, "la Revolución atómica llevó a una situación tal a las ciencias, que el hombre perdió hasta la objetividad del mundo natural [...], de repente descubrió que está siempre confrontado a él mismo, e incluso a él sólo" (Arendt, 1972, p. 352). En estas condiciones, el discurso y el lenguaje habituales, pronto habrían dejado realmente de ser una expresión significativa que trasciende el comportamiento, para ser ventajosamente reemplazados por símbolos matemáticos sin sentido.

Hannah Arendt asimila el acosmismo ${ }^{1}$ a una forma genuina de la barbarie. El sionismo era un nuevo acosmismo que se caracterizaba por el desconocimiento de la alteridad y de la pluralidad árabe: el pueblo judío huyó a Palestina para escapar de la maldad del mundo. Vemos entonces que la esperanza se basa en una expectativa, en un milagro. Y no es él del superhombre, "especie humana lo suficientemente fuerte para vivir en el pensamiento del eterno retorno", capaz de trascenderse, de "superarse", sino el que se renueva con la llegada de todo recién nacido (Arendt, p. 19).

Por otra parte, Heidegger interpreta el mito de la caverna como una "bajada del hombre liberado de la cueva". Aquí, Heidegger llega a prever una pelea en el interior de la cueva entre "el libertador y los presos que se oponen a cualquier liberación" (Abensour, 2006, p. 80). En la reflexión de Platón, según Hannah Arendt, la bajada a la cueva está, por lo tanto, estrechamente relacionada con la aplicabilidad de las ideas y con su utilidad en el campo político. Escribe a este respecto: "Es sólo cuando el filósofo baja a la oscura caverna de los asuntos humanos para vivir de nuevo con sus compañeros, cuando necesita de las ideas que le servirán como guía para criterios y reglas. Con ellos podrá subsumir y medir la multitud variada de las acciones y de los discursos de los hombres" (Arendt, 1972, p. 151). Para Heidegger, por el contrario, hay 
que retirarse completamente de la esfera de los asuntos humanos. Solo entonces el pensamiento se vuelve auténticamente especulativo. Según Hannah Arendt, si por desgracia el pensador deja este lugar contemplativo, es para comprometerse con los tiranos y dictadores. Heidegger vio en el nacional-socialismo el encuentro de la técnica que se volvió planetaria y del hombre de los Tiempos Modernos.

Según Arendt, el compromiso con los tiranos y dictadores es una deformación profesional (Arendt, p. 318). Esta "deformación profesional" se refleja en la entrada de Heidegger en el Partido Nazi (NSDAP) el 1 de mayo de 1933, y como rector de la Universidad de Friburgo. Heidegger comparte ciertos aspectos de la ideología nazi, pero no el anti-semitismo, ni el aspecto racial, ni su biologismo, ni la mística científica, ni su ideología simplista y mecanicista, que considera grosera, y que imagina, precisamente por eso, poder transformarla filosóficamente.

Heidegger descubre en la revolución nacional-socialista un acontecimiento metafísico fundamental, una "transformación del Dasein alemán", tal y como lo expresó en su discurso en Tübingen el 30 de noviembre de 1933. Heidegger está en busqueda de un nuevo suelo (filosófico) que no sea, ni el de la sangre, ni él de la raza. Sin embargo, comparte con Baümler el pensamiento de la decisión pura. De hecho, Heidegger, como rector, por un lado, defendió y ayudó a sus propios estudiantes judíos que le pidieron apoyo para salir de Alemania; y, por otro lado, prohíbe a los estudiantes nazis pegar en las paredes de la universidad carteles antisemitas. No se encuentra en él ningún rastro de antisemitismo, ni tampoco racismo, lo que Jaspers certificará en su informe de 1945. Hannah Arendt defendió así mismo a Heidegger, excepto cuando le llama: "el zorro que hace su madriguera".

Al vincular el pensamiento de Sócrates con el de Heidegger, Hannah Arendt combina dos modos de comprensión: él de los griegos y él de los fenomenólogos. Esta comprensión no viene del sentimiento humano, sino más bien del espacio político, y sigue siendo el mundo común. En este punto, la definición de Hannah Arendt sobre la libertad de pensamiento se torna específica: el pensar se limita a la esfera del sentido, confinado en un espacio espiritual, en el cual se va a entender lo que es la libertad (Moreault, 2002, p. 79). Hannah Arendt, Heidegger y Sócrates concuerdan en el estatus de la actividad de pensar: el pensar es una actividad que arrasa todo y no deja rastro alguno.

Para Heidegger, el Ser en sí mismo, en un perpetuo cambio, se manifiesta en el pensamiento del que actúa, de modo que el pensar y el actuar coinciden: actuar significa echar una mano a la esencia del Ser, es decir, preparar el lugar donde el Ser se lleva y lleva su esencia al lenguaje. El lenguaje es el único que da vía y paso a toda voluntad de pensar (Arendt, 2005, p. 497). El actuar de Heidegger es silencioso, es una acción completamente interior por la cual el hombre se abre a la realidad auténtica. Es probablemente la razón por la cual Heidegger, desde el inicio hasta el fin de su obra, evita intencionalmente tratar el tema de la acción. Heidegger también hace referencia a la voz del amigo que todo Dasein (existencia humana) lleva consigo: la actitud del hombre, confrontado al Ser, puede ser entendida como una variante del thaumazein de Platón, primera experiencia de la filosofía (Heidegger, 1986, p. 229.

La diferencia fundamental con Heidegger se expresa inmediatamente después del reconocimiento: Hannah Arendt no piensa simplemente; ella piensa lo político, nuestra historia política (Cassin, p. 21). Por el contrario, el pensar, dice Heidegger, es el acercamiento de lo lejos: "El pensar aleja el cercano, es decir se retira del cercano, y acerca lo alejado; esto es crucial si se quiere evidenciar la estadía del pensar" (Arendt, p. 316).

La crítica de Hannah Arendt sugiere que la metafísica del Dasein es, en última 
instancia, la transformación de la filosofía en antropo-teo-logía, debido al "desconocimiento de la condición política del ser humano, es decir la pluralidad" (Tassin, 2009, p. 116). En Hannah Arendt se encuentra una antropología existencial $a$ priori. Incluye los conceptos kantianos de libertad y de la dignidad humana en un sentido político del mundo. Por el contrario, Heidegger ve en la antropología el olvido del tema del ser del hombre. Para Heidegger, el actuar es ontológico; para Hannah Arendt es político. Por eso Hannah Arendt dice: "Heidegger se equivoca: el hombre no está "abandonado" en el mundo; y si estamos abandonados, ¿qué nos diferencia de los animales? Al contrario, el hombre está precisamente acompañado, y no abandonado en el mundo, y es en esto donde reside su continuidad y se manifiesta su pertenencia. ¿Qué sería de nosotros si estuviéramos abandonados en el mundo" (Arendt, 2005, p. 743).

La crítica de Hannah Arendt se centra en la ontología de Heidegger que nunca se constituyó realmente, ya que el segundo volumen de Ser y Tiempo nunca fue publicado. $\mathrm{Su}$ respuesta, provisional y como tal difícil de entender, a la pregunta sobre el sentido del ser, fue contestar que el sentido del ser es la temporalidad. Esto equivale a establecer, implícitamente y por el análisis del Dasein (es decir del ser-ahí, del ser del hombre) determinado por la muerte, que el sentido del ser era la nada. De este modo, el intento de Heidegger para reformular la metafísica ha fallado (Arendt, 2002, p. 52).

Hannah Arendt, a propósito de la muerte dice: "Mientras vivimos en esta tierra, necesitamos tanto a los demás como necesitaremos a Dios en la hora de nuestra muerte, es decir cuando saldremos de la tierra" (Arendt, p. 239). Esto significa la necesidad de pluralidad mientras estamos vivos. Esta referencia es vital para la comprensión acerca de si Hannah Arendt era una mujer creyente o no. Al respecto cabe decir que su teoría política tiene muchísima influencia hebrea y cristiana; por ejemplo, su tesis doctoral es sobre San Agustín. El perdón y la promesa tienen mucha influencia y aplicación incluso para el campo de la fe. Lo que si se siente en Hannah Arendt es el dolor del abandono y el distanciamiento de las autoridades eclesiásticas respecto al holocausto judío.

Hemos visto que hay un distanciamiento respecto a su profesor Heidegger; sin embargo, hay cierta cercanía en lo que se refiere a tres elementos del pensamiento de Heidegger:

a) La actividad de pensar es una meditación, pero no una contemplación. Es más bien "destructiva" o "deconstructiva". Esto tiene como resultado que el pensar se comporta de una manera destructiva hacia sus propios resultados, es decir que se transforma en un pensamiento crítico (Arendt, p. 313).

b) Este pensar no sigue ninguna meta, no engendra nada, pero plantea "hitos" que, marcando el camino del pensamiento, guían "un nuevo curso del pensar": no se piensa en vista de cualquier resultado que sea; es decir, que un pensamiento no debe ser calculante, un medio para una determinada finalidad.

c) Este pensar es político en la medida en que trata de comprender todo lo que es, y entonces, piensa otra vez lo que ya se ha pensado. El pensar, según Heidegger, toma fuerza desde el "ser-nacido-en-el-mundo". De acuerdo con el análisis de Hannah Arendt, Heidegger no hace ninguna mención de la relación entre el pensar y el agradecer, lo que conlleva eventualmente a conclusiones pesimistas, por no decir nihilistas (Arendt, 2005, p. 512). Pensar y ser vivo se convierten en uno: "Heidegger mismo, expresó una vez esta fusión" (Arendt, p. 312). Esto significa que todo aquel que no piensa y se expresa por sí mismo, que se resigna a que piensen por él, está muerto a la vida política.

La intención filosófica de Heidegger podría resumirse así: desconstruir la metafísica occidental para redescubrir la ontología. La mayoría de los intérpretes consideran que las tesis de Heidegger, especialmente aquellas desarrolladas en Sein und 
Zeit (Ser y tiempo), en comparación con las de Hannah Arendt, muestran la ausencia de pensamiento político. Sus conceptos existenciales están, de facto, exentos de historicidad. Heidegger parece despreciar la esfera política cuando, en un momento dado, acusa a Hannah Arendt de buscar publicidad, espacio donde falta autenticidad, y que lleva a todas las ilusiones a las cuales se entrega el Dasein, ayudando a ocultar el acceso a su verdad existencial. Además, Heidegger no presta atención suficiente a la nacionalidad, de donde surgen la mayoría de los problemas políticos de los pueblos. Promueve así la indiferencia en política con sus definiciones "neutras" de la existencia humana, a partir de las cuales ningún análisis político se puede desarrollar, ninguna decisión puede ser tomada en relación con una coyuntura histórica y política definida. Sin embargo, Heidegger admite la grandeza de un proyecto político con alcance mayor, aunque su pensamiento resulta finalmente incompatible con el nazismo, tal y como se desarrolla en la misma época.

\section{CONCLUSIONES}

Para concluir cabe decir que Heidegger no es un pensador de respuestas, sino más bien de preguntas. Se asemeja a un principiante que comienza con la capacidad de sorprenderse, de angustiarse, de curiosidad, e incluso de júbilo. Manifiesta que siempre hay que volver a nacer, para hacer una vida verdaderamente humana (Safranski. p. 14).

Es innegable que Heidegger se sentía muy bien en medio de la gran burguesía conservadora liberal. No así Arendt quien, a pesar de que nunca dijo expresar o compartir discursos de izquierda, si favoreció a los apátridas, a los pobres en derechos. Heidegger no elabora una filosofía constructiva, una concepción del mundo, o una doctrina moral. Su pasión fue siempre el preguntar acerca del ser, y no tanto de responder.

Hannah Arendt busca en la Grecia antigua la escena primitiva del pensamiento. Heidegger tiene su parábola de la caverna de Platón. Hannah Arendt tiene la imagen de la democracia griega, tomada prestada de Tucídides. Ella no cree en la luz platónica de la verdad perfecta. La filosofía de la natalidad de Hannah Arendt es una respuesta a la filosofía de la mortalidad de Heidegger. Justamente a partir de la filosofía del podercomenzar, Arendt elabora su concepto de democracia.

El filósofo Heidegger afirma un saber vivir en el espíritu. Aunque no es confesional, podríamos decir que pone a Dios entre paréntesis. Es aquí donde radica la diferencia radical entre Heidegger y Hannah Arendt: el primero se orienta al espíritu desde una perspectiva ontológica con implicaciones políticas; mientras que la segunda toma el camino del espacio público, lugar de debate y de participación ciudadana. Lo que trata de promover la teoría política de Arendt, es que haya ciudadanos pensantes, que salgan de su pasividad y del mundo del mercado (lugar donde solo aparecen para comprar o vender productos) y que actúen políticamente. Este punto es fundamental, ya que aún persisten en las democracias actuales, actitudes de lealtad ciegas y no pensantes. Tampoco es que el discurso de las libertades se ha agotado. Es necesario una pedagogía que promueva e incentive la libertad. Y en esta historia de progreso, aunque Arendt no lo considere necesario, el cristianismo ha sido un pilar fundamental en hechos históricos en América latina.

Hannah Arendt muere el 4 de diciembre de 1975 y Heidegger el 26 de mayo de 1976. Este último esperaba su muerte calmada y serenamente. En enero, invita a Bernhard Welfe, un profesor de teología de Friburgo para que venga a conversar con él. Heidegger manifiesta que desearía ser enterrado en el cementerio de MeBkirch en una 
ceremonia religiosa, y le pide un discurso cerca de su tumba. Así se despide el pensador que un día había desechado los dogmas de la Iglesia Católica, pero que en las Iglesias se persignaba con agua bendita y hacia genuflexión. Cuando sus amigos le preguntaban el porqué de esa actitud, Heidegger se justificaba diciendo: "Hay que pensar históricamente. En el lugar donde se oró un día, lo divino está cerca de una manera particular" (Muller, 1998, p. 213).

Para terminar, habría que citar sin duda la frase que Heidegger pronunció en el inicio de un curso en Marbourg, luego de la muerte de Max Scheler: "Un camino de la filosofía regresa a la obscuridad" (Safranski, p. 452).

\section{REFERÉNCIAS}

ABENSOUR, M., Hannah Arendt contre la philosophie politique ? Paris, Sens et Tonka, 2006.

ARENDT, H., KARL JASPERS, La philosophie n'est pas tout à faitinnocente, Paris, Payot, 2006.

ARENDT, H., La vie de l'esprit, Paris, Puf, 2005. . Journal de pensée. Vol II, Paris, Seuil, 2005. . Journal de pensée. Vol I, Paris, Seuil, 2005. . Condition de l'homme moderne, Paris, Gallimard, 2002. - ¿Qu'est-ce que la philosophie de l'existence? Paris, Payot\&Rivages, 2002. . La philosophie de l'existence, Paris, Payot, 2000.

. La crise de la culture, Paris, Gallimard, 1972.

ARENDT, H., Martin Heidegger à quatre-vingts ans, Vies politiques, Paris, Gallimard, 1974, p. 313

BLAIS, Claude-Marie, Au principe de la République, Le cas Renouvier, Paris, Gallimard, 2000.

CASSIN, B., Grecs et Romains: les paradigmes de l'Antiquité chez Arendt et Heidegger, Politique et pensée, Colloque Hannah Arendt, Paris, Payot \& Rivages, 1996.

COURTINE-DENAMY, S., Le Sahara en Afrique n'est qu'une forme de désert, en H. Arendt, Qu'est-ce que la politique?, Paris, Seuil, 1995.

DERUELLE, Edouard, Le consensus impossible, Bruxelles, Ousia, 1993.

GARCIA, Ana María, Del poder del discurso al discurso del poder, Buenos Aires, Eudeba, 2001.

HEIDEGGER, M., Phénoménologie de la vie religieuse, Paris, Gallimard, 2012. . Etre et temps, Paris, Gallimard, 1986. .Écrits politiques, Paris, Gallimard, 1977. . Approche de Hölderlin, Paris, Gallimard, 1973.

MOREAULT, F., H. Arendt, l'amour de la liberté, Québec, Les Presses de l’Université Laval, 2002.

MULLER, Max, "Martin Heidegger, EinPhilosophund die Politik", en G. Neske/E. Kettering (editores), Antwork. Martin Heidegger im Gespräch, Pfullingen, 1998.

RICOEUR, Paul, Préface, ARENDT, H., Condition de l'homme moderne, Paris, Gallimard, 2002.

SAFRANSKI, Rüdiger, Heidegger et son temps, Paris, Grasset, 1996.

TAMINIAUX, J. Heidegger y Arendt, Lille, Les Cahiers de Philosophie 4, 1988.

TAMINIAUX, J., ¿Arendt, discíple de Heidegger ?, Etudes phénoménologiques, 1985.

TASSIN, E., Le trésor perdu : Hannah Arendt, l'intelligence de l'action politique, Paris, Payot, 2009.

\section{Notas}

1 Se refiere a lo contrario a la vida creada, la negación de la pluralidad y la armonía. 